\title{
Antibiotic treatment and associated prolonged prothrombin time
}

\author{
K J Williams, R P Bax, H Brown, S J Machin
}

\begin{abstract}
The incidence and type of pathology causing a prolonged prothrombin time and clinical bleeding episodes were assessed in a multicentre study of 1109 patients receiving cefotetan, a $\mathbf{N}$-methylthiotetrazole (NMTT), or equivalent antibiotics. There was no significant difference in the incidence of a prolonged prothrombin time $(\mathbf{9 . 9} \%$ with cefotetan, $8.0 \%$ with comparable antibiotics) of clinical bleeding episodes. However, prothrombin time increases of greater than 12 seconds were significantly ( $p=$ $0.002)$ greater with cefotetan $(3.8 \%)$ than with comparators $(0.8 \%)$. In both antibiotic groups increases in prothrombin time were more likely following surgery and in patients who were older, with a high platelet count, low albumin, or higher urea and creatinine concentrations. All antibiotic treatment can be associated with prolonged prothrombin times and new agents should always be assessed in a large multicentre study before the practical, clinical importance of haemostatic defects can be defined.
\end{abstract}

There are numerous causes of acquired defects of the haemostatic mechanism, usually associated with multisystem disease, or drug treatment, which are responsible for, or precipitate, clinical bleeding episodes. ${ }^{1}$

When such events occur, or are expected, a series of simple laboratory screening tests, which are easy to perform and give reliable results quickly, are routinely undertaken. ${ }^{2}$ The one stage prothrombin time is an essential test in all haemostatic screening procedures and increases of five seconds or more above the control range, in our experience, are particularly associated with clinical bleeding events. For many years antibiotic treatment has been implicated in various changes in the normal haemostatic process and precipitating bleeding. ${ }^{34}$ Recently hypoprothrombinaemia and a prolonged prothrombin time have been specifically reported in association with several antibiotics, particularly cephamandole, moxalactam, and cefoperazone..$^{5-7} \mathrm{~N}$-methylthiotetrazole (NMTT) containing antibiotics, such as moxalactam and NMTT alone, inhibit the vitamin $\mathrm{K}$ dependent carboxylation of glutamic acid residues in liver cells. ${ }^{8}$

Most clinical reports have emphasised, however, that a malnourished or debilitated condition with relative vitamin $\mathrm{K}$ deficiency is also present before pathological increases in the prothrombin time and bleeding events occur. ${ }^{910}$ With the background of multisystem disease and concurrent drug treatment it is difficult to implicate a single antibiotic in a specific haemostatic defect such as a prolonged prothrombin time. To do this, the effects of sepsis, surgery, and any underlying medical condition such as renal or liver failure would have to be separated from those of the antibiotic itself on prolonging the prothrombin time. Because of these problems there have been very few controlled studies of prolonged clotting times associated with specific antibiotic regimens. ${ }^{11}$ Conflicting evidence has been published about the ability of relatively new NMTT containing antibiotics such as cefotetan to affect the prothrombin time and cause clinically important bleeding. ${ }^{12-14}$

Adverse reports are usually from one or two isolated cases which are often not corroborated by independent review. The importance of this problem has been highlighted by the regulatory licensing authorities insisting that prothrombin time data are now submitted when clinical trials with cephalosporin antibiotics are being designed and that reports are filed with all new antibiotics. This report evaluates how an open, random, comparative multicentre study was designed to investigate the incidence and degree of prothrombin time increases in patients being treated with intravenous cefotetan, which has the NMTT side chain, or comparator antibiotics, which do not, and the contribution of any associated risk factors.

\section{Methods}

A total of 1109 patients in 19 centres throughout Europe and South Africa were randomly chosen to receive either cefotetan $(n=555)$ or comparator antibiotic(s) $(n=554)$, none of which contained the $\mathrm{N}$-methylthiotetrazole (NMTT) side chain. The comparators were those given as standard practice in each centre and these included cefotaxime ( $\mathbf{n}=250)$, benzyl penicillin or ampicillin/metronidazole and gentamicin $(n=218)$, cefoxitin plus metronidazole $(n=12)$, cefoxitin $(n=45)$ and cephradine plus metronidazole $(n=29)$.

Children and pregnant women were excluded from the study and so were patients with known allergy to cephalosporins or to the alternative comparative treatment. Patients receiving other investigational or concurrent 
Table 1 Demographic details of study population

\begin{tabular}{lll}
\hline & $\begin{array}{l}\text { Group taking } \\
\text { cefotetan } \\
\text { (CTT) }\end{array}$ & $\begin{array}{l}\text { Group taking } \\
\text { comparators }\end{array}$ \\
\hline Number of patients & 555 & 554 \\
Sex & & \\
$\quad$ Males & 248 & 249 \\
Females & 307 & 303 \\
Mean age (years) & 54 & 54 \\
Age range (years) & $14-89$ & $12-93$ \\
Site of primary infection & 243 & 235 \\
Intra-abdominal & 117 & 110 \\
Urinary tract & 61 & 73 \\
Respiratory tract & 54 & 54 \\
Soft tissue & 64 & 62 \\
Obstetric/gynaecological & 16 & 20 \\
Other & & \\
\hline
\end{tabular}

antimicrobial drugs were excluded. The demographic data are summarised in table 1.

All patients gave their informed consent for inclusion in the study and the study protocol was reviewed by the local ethical committees. A record form specifically designed for the study recorded data on factors which were potentially likely to affect prothrombin time. These included the history of antibiotics and operations in the preceding month. Any abnormal blood loss in this pretreatment period was recorded along with details of the event, possible cause, intensity, actions and outcome. During this period and the trial, details of the administration of blood or blood products, vitamin $\mathrm{K}$, warfarin, heparin, parenteral nutrition, non-steroidal anti-inflammatory agents, steroids, aspirin or other relevant drugs were recorded.

If vitamin $\mathrm{K}$ was administered during the study it was recorded whether this was part of routine hospital practice, due to the finding of an abnormal prothrombin time on admission, or to an increase during the study period. In all cases the date of first administration of vitamin $\mathrm{K}$ was also noted. Details of all abnormal blood loss of whatever cause continued to be recorded during antibiotic treatment and immediately after treatment. In addition to a routine biochemical profile, full blood count, platelet count and differential, the one stage prothrombin time and normal control time were recorded in seconds. Such tests were performed immediately before treatment, during and at the conclusion of treatment, and at follow up, about 10 days after completion of treatment.

As the prothrombin times were measured in 16 different laboratories using different types of thromboplastin, the normal range varied between 11 and 16 seconds. Prolongation of the prothrombin time was defined as a five second increase outside the upper limit of the normal
Table 3 Range of significant increases in PT

(percentages are of evaluable patients)

\begin{tabular}{lll}
\hline & \multicolumn{2}{l}{ Treatment } \\
\cline { 2 - 3 } & Cefotetan & Comparators \\
Range of significant increase & $N(\%)$ & $N(\%)$ \\
\hline No significant increase & $454(90.0)$ & $461(92.0)$ \\
5-12 seconds & $31(6.2)$ & $36(7 \cdot 2)$ \\
$>12$ seconds & $19(3.8)$ & $4(0.8)$ \\
Total & $504(100.0)$ & $501(100.0)$ \\
\hline
\end{tabular}

«Significantly different $(p=0.002)$.

range, representing a significant change using European thromboplastins. In many of the patients with initially abnormal prothrombin times or with changes during treatment, a daily prothrombin time was recorded. Details of operations performed during treatment were recorded as well as a full history of all concurrent drugs, especially those known to affect the prothrombin time such as heparin, warfarin, and aspirin. The doses of both cefotetan or comparators were chosen to reflect the severity and site of the infection.

$\chi^{2}$ tests were carried out to test whether there was a significant association between treatment and incidence of a prothrombin time increase of over five seconds and with bleeding events during the study. The means of the prothrombin time increase for each treatment group were compared using a $t$ test, because the mean of any distribution approaches normality as the number of observations becomes larger.

The $t$ test was also used to detect differences in prothrombin time increases in the subgroups with surgery either during or before treatment, those with an already raised prothrombin time (more than five seconds), bleeding events before treatment and those receiving steroids, parenteral nutrition, or heparin:

For the multifactorial risk analysis, laboratory values were converted to the same units when necessary. Extreme outliers were found in some of the initial parameters at trial entry and these were incorporated into equations at the top of a defined clinically "sensible" range. In rare cases when a value was missing, a mean value was inserted. This leads to a smaller loss of variability than would have occurred if the patient was omitted, as happens in logistic regression.

\section{Results}

The general condition of the patients and the severity of the major infection were similar in the two groups. A total of $883(79.6 \%)$ had not received any antibiotics in the four weeks

Table 2 Incidence of prothrombin time changes of over five seconds

\begin{tabular}{|c|c|c|c|c|c|c|}
\hline & \multicolumn{2}{|c|}{$\begin{array}{l}\text { Number of } \\
\text { evaluable patients }\end{array}$} & \multicolumn{2}{|c|}{$\begin{array}{l}\text { Number with a } \\
\text { prolongation of }>5 \mathrm{~s}\end{array}$} & \multicolumn{2}{|c|}{$\begin{array}{l}\text { Percentage } \\
\text { with }>5 \text { seconds change }\end{array}$} \\
\hline & $C T T$ & Comparators & $C T T$ & Comparators & $C T T$ & Comparators \\
\hline All patients & 504 & 501 & 50 & 40 & $\begin{array}{l}9 \cdot 9 \\
(3 \cdot 7-16 \cdot 1)\end{array}$ & $\begin{array}{l}8 \cdot 0 \\
(2 \cdot 5-13 \cdot 5)\end{array}$ \\
\hline $\begin{array}{l}\text { Patients with initial PT } \\
\text { prolonged }\end{array}$ & 79 & 105 & 11 & 9 & $\begin{array}{l}13.9 \\
(7 \cdot 2-23 \cdot 6)\end{array}$ & $\begin{array}{l}8 \cdot 6 \\
(4 \cdot 0-15 \cdot 7)\end{array}$ \\
\hline
\end{tabular}

Figures in parentheses are $95 \%$ confidence intervals. 
Table 4 Individual variables significantly associated with prothrombin time increase

\begin{tabular}{|c|c|c|c|c|}
\hline \multicolumn{2}{|l|}{ Risk factor } & $\begin{array}{l}P T \text { increase } \\
<5 s\end{array}$ & $\begin{array}{l}P T \text { increase } \\
5-12 \mathrm{~s}\end{array}$ & $\begin{array}{l}P T \text { increase } \\
>12 \mathrm{~s}\end{array}$ \\
\hline $\begin{array}{l}\text { Operation during } \\
\text { Yes } \\
\text { No } \\
\text { Age (years) } \\
\text { Platelets } \times 10^{9} / 1 \\
\text { Albumin } \mathrm{g} / 1 \\
\text { Urea mmol } / 1 \\
\text { Creatinine } \mu \mathrm{mol} / 1\end{array}$ & $\begin{array}{l}\text { tibiotic cours } \\
\text { Mean (SD) } \\
\text { Mean (SD) } \\
\text { Mean (SD) } \\
\text { Mean (SD) } \\
\text { Mean (SD) }\end{array}$ & $\begin{array}{c}339(85 \cdot 2 \%) \\
569(94 \cdot 8 \%) \\
53 \cdot 7(21 \cdot 7) \\
304(131) \\
39 \cdot 1(11 \cdot 9) \\
6 \cdot 2(3 \cdot 8) \\
99(42)\end{array}$ & $\begin{array}{c}41(10 \cdot 3 \%) \\
24(4 \cdot 0 \%) \\
58 \cdot 4(22 \cdot 7) \\
328(158) \\
34 \cdot 8(10 \cdot 9) \\
7 \cdot 5(5 \cdot 4) \\
106(50)\end{array}$ & $\begin{array}{c}18(4 \cdot 5 \%) \\
7(1 \cdot 2 \%) \\
68 \cdot 1(20 \cdot 2) \\
320(94) \\
32 \cdot 5(7 \cdot 9) \\
13 \cdot 4(10 \cdot 4) \\
166(71)\end{array}$ \\
\hline
\end{tabular}

Factors significantly associated with a prothrombin change greater than 5 seconds calculated for all 1005 assessable cases by performing a least squares regression.

Age

$\quad(p=0.0011)$

Platelets $\quad(\mathrm{p}=0.0462)$

Albumin $\quad(\mathrm{p}=0.0007)$

Creatinine $\quad(p=0.0001)$

No other clinical biochemical or haematological variables were significantly associated with a prothrombin time increase. tics and laboratory data available showed that six clinical and laboratory variables were significantly related to the development of a prolonged prothrombin time (table 4).

The incidence of clinical bleeding events related to antibiotic use and prothrombin time changes are summarised in table 5 . There was no difference between the incidence of bleeding events and treatment group, but bleeding was more common in patients with prolonged prothrombin times.

\section{Discussion}

Although dose ranging studies on standard haemostasis tests in healthy volunteers are important in determining the safety profile during the development of all new antibiotics, they can give rise to a sense of false security. Indeed, several volunteer studies showed no increases in prothrombin time with moxalactam. ${ }^{15}{ }^{16}$ Only when the antibiotic is tested in large multicentre trials and patients with varying multisystem disease are given the drug can the potential effects on the prothrombin time be assessed properly. Most clinical trials include too few patients to assess uncommon events. This large multicentre study showed no significant difference in the number of subjects who developed a prolonged prothrombin time between those who received cefotetan alone $(9.9 \%)$ or comparator antibiotics $(8.0 \%)$ despite including 1109 patients. Only when those patients with increases of 12 seconds or more (3.8\% with cefotetan and $0.8 \%$ with comparator antibiotics) were analysed was a significant difference between the groups found ( $p$ $=0.002$ ). There was no difference in clinical bleeding episodes between the two antibiotic treatment groups. The study, however, was able to show that in both treatment groups increases of prothrombin time were more likely to occur if the patients had an operation, were older, had a high initial platelet count, a lower serum albumin concentration, or higher urea and creatinine concentrations.

Regardless of the precise biochemical mechanism, malnutrition and vitamin $K$ deficiency are more common in older patients with low serum albumin concentrations, and are likely to be acutely accentuated during gastrointestinal surgery when little oral nutrients are received in the first few preoperative days. ${ }^{17}$ Indeed, these theories have been proved in a small group of elderly postoperative patients receiving cefotetan with clinical features of malnutrition and low serum vitamin $\mathrm{K}_{1}$ concentrations. ${ }^{18}$

Table 5 Clinical bleeding events

\begin{tabular}{|c|c|c|c|c|c|c|}
\hline & \multicolumn{2}{|c|}{$\begin{array}{l}\text { Number of patients } \\
\text { evaluable }\end{array}$} & \multicolumn{2}{|c|}{$\begin{array}{l}\text { Number of bleeds } \\
\text { (during or at follow up) }\end{array}$} & \multicolumn{2}{|c|}{$\begin{array}{l}\text { Percentage of patients } \\
\text { with bleeds }\end{array}$} \\
\hline & $C T T$ & Comparators & $C T T$ & Comparators & $C T T$ & Comparators \\
\hline No significant increase in PT & 454 & 461 & 31 & 26 & \multirow{3}{*}{$\begin{array}{l}6 \cdot 8 \\
(1 \cdot 7-1 \cdot 9) \\
12 \\
(5-24) \\
7 \cdot 3 \\
(2 \cdot 0-12 \cdot 6)\end{array}$} & \multirow{3}{*}{$\begin{array}{l}5 \cdot 6 \\
(0 \cdot 4-10 \cdot 6) \\
10 \\
(3-24) \\
6 \cdot 0 \\
(0 \cdot 9-11 \cdot 1)\end{array}$} \\
\hline Increase $>5$ seconds & 50 & 40 & 6 & 4 & & \\
\hline All patients & 504 & 501 & 37 & 30 & & \\
\hline
\end{tabular}


Renal impairment, as well as affecting the elimination of antibiotic, may predispose to variable coagulation factor deficiencies, hepatic cell dysfunction, and uraemic enteritis, all of which can contribute to a prolonged prothrombin time. ${ }^{19}$ Studies of the newer agents, especially the cephamycins, moxalactam, and cefotetan, have commonly included such compromised patients. We have shown, however, that all antibiotics, especially when given to patients in the above high risk categories, may coincidentally be associated with a prolonged prothrombin time, predisposing in some cases to clinical bleeding events. Prothrombin time alone is a poor indicator of vitamin $\mathrm{K}$ state and it may be appropriate to administer vitamin $\mathrm{K}$ to patients with the defined risk factors In patients without these risks the NMTT containing antibiotic, cefotetan, did not cause more rises of prothrombin time than alternative antibiotics. Single case reports of antibiotic associated hypothrombinaemia, which have been repeatedly reported, must now be judged against similar control groups receiving comparative antibiotic treatment. Only when such data are available can the true incidence and clinical importance of such events be judged. The results provided in this paper should provide guidance regarding the types of patients in the high risk categories.

We acknowledge the participation of the following people: From England: S Scott, S Karran, P Billings, D J Leaper, $J$ Alexander Williams and $M$ R B Keighley.

From Germany: Drs R Hautmann, M Pfeiffer, H Hessler, $K$ Lossnitzer, H K Horsch, N Lang and U Lochmueller. From South Africa: Dr M Marivate. From Italy: Professor Rondanelli.
1 Machin SJ. Acquired disorders of haemostasis. In: Hoffbrand AV, Lewis SM, eds. Postgraduate haematology. Hoffbrand AV, Lewis SM, eds. Post

2 Machin SJ, Mackie IJ. Laboratory haematology. Edinburgh: Churchill Livingstone, 1989.

3 Ham JM. Hypoprothrombinaemia in patients undergoing prolonged intensive care. Med J Aust 1971;2:716-18.

4 Brown CH, Natelson EA, Bradshaw MW. The haemostatic defect produced by carbenicillin. $N$ Engl J Med 1974 291:265-70.

5 Hooper CA, Haney BB, Stone HH. Gastrointestinal bleeding due to vitamin $\mathrm{K}$ deficiency in patients on parenteral cefamandole. Lancet 1980; i:39-40.

6 Pakter RL, Russell TR, Mielke CH, West D. Coagulopathy associated with the use of moxalactam. JAMA 1982; 248:1100-5.

7 Weitekamp MR, Caputo GM, Al-Mondhiry HAB Aber RC. The effects of latamoxef, cefotaxime and ceftoperazime in platelet functions and coagulation in norma volunteers. J Antimicrob Chemother 1985;16:95-101.

8 Lipsky JJ. Mechanisms of the inhibition of the gammacarboxilation of glutamic acid by $\mathrm{N}$-methylioltetrazolecontaining antibiotics. Proc Natl Acad Sci USA 1984 81:2893-7.

9 Bechtold H, Andrassy K, Jahnchen E, et al. Evidence for impaired hepatic vitamin $K_{1}$ metabolism in patients treated with $\mathrm{N}$-methyl-thiotetrazole cephalosporins. Thromb Haemostas 1984;51:358-61.

10 Mackie IJ, Walshe, $\mathrm{K}$, Cohen $\mathrm{H}$, et al. The effects of a NMTT-cephalosporin on haemostasis in patients with NMTT-cephalosporin on haemostasis in patients with
reduced serum vitamin $K_{1}$ levels. J Clin Pathol 1986; reduced serum

11 Baxter JG, Marble DA, Whitfield LR, Wels PB, Walczak P, Schentag JJ. Clinical risk factors for prolonged PT/PTT in abdominal sepsis patients treated with moxolactam or tobramycin plus clindamycin. Apn Surg 1985;201:96-102.

12 Cohen H, Mackie IJ, Walshe K, ef al. The effects of cefotetan disodium on haemostasis. J Hosp Infect 1987;10:51-7. 13 Holt J. Hypoprothrombinaemia and bleeding diathesis Arch Surg 1988;123:523.

14 Smith KS, Quintiliani R, Nightingale $\mathrm{CH}$. Cefotetan associated coagulopathies. Arch Surg 1989;124:388.

15 Bang NU, Tessler SS, Heidenreich RO, Marks CO, Mattler LE. Effects of moxalactam on blood coagulation Mattler LE. Effects of moxalactam on blood coagulation
and platelet function. Rev Infect Dis 1982;4:S546-54.

16 Bowcock S, Mackie IJ, Mo D, Moulsdale M, Billings P, Machin SJ. Effects of various doses of latamoxef on haemostasis. J Hosp Infect 1986;8:193-9.

17 Karran SJ, Alberti KGM. Practical nutritional support. London: Pitman Medical, 1980.

18 Cohen H, Scott SD, Mackie IJ, et al. The development of hypoprothrombinaemia following antibiotic therapy in malnourished patients with low serum vitamin $K_{1}$ levels. Br J Haematol 1988;68:63-6.

19 Remuzzi G. Bleeding in renal failure. Lancet 1988;i:1205-8. 